\title{
Forcing of the Wintertime Antarctic Boundary Layer Winds from the NCEP-NCAR Global Reanalysis
}

\author{
Thomas R. PARish AND JOHn J. CASSANO \\ Department of Atmospheric Science, University of Wyoming, Laramie, Wyoming
}

(Manuscript received 3 April 2000, in final form 12 July 2000)

\begin{abstract}
Antarctica is noted for strong and persistent winds in the lower atmosphere. The wind directions are controlled by the underlying ice terrain and are deflected in general $20^{\circ}-50^{\circ}$ to the left of the fall line. The Antarctic surface wind regime is thought to be the result of the dual influences of diabatic cooling of the terrain, responsible for the infamous katabatic winds, and the synoptic pressure gradient force in the free atmosphere. The relative importance of pressure gradients associated with katabatic and synoptic processes in forcing the wintertime Antarctic boundary layer winds is evaluated using output from the National Centers for Environmental PredictionNational Center for Atmospheric Research (NCEP-NCAR) global reanalysis program for June, July, and August of 1997. Both katabatic and synoptic forces are found to be significant in shaping the near-surface winter winds over the Antarctic ice slopes. Analyses show that the synoptic force is influenced by the underlying ice terrain such that the net force over Antarctica is directed primarily downslope. This result reflects the adjustment of the large-scale ambient pressure gradient to the continental orography. The synoptic force over Antarctica thus differs significantly in both magnitude and direction from that found over the oceanic regions to the north. The adjustment of the synoptic force over the ice sheets enable even the nonwinter Antarctic winds to attain a high directional constancy and resemble a gravity-driven flow. This process also suggests that direction alone is insufficient in classifying Antarctic flows as katabatic.
\end{abstract}

\section{Introduction}

Four decades have passed since Ball's pioneering work on Antarctic winds (Ball 1956, 1957, 1960). Ball (1960) viewed the low-level wind regime over the ice sheet as a well-mixed, relatively thin layer of radiatively cooled air capped by a temperature inversion. A steadystate flow was assumed in which the layer-averaged forces of horizontal pressure gradient, Coriolis, and friction achieve a balance. Mathematically, the equations of motion can be expressed as

$$
\begin{aligned}
& 0=F-f v-\frac{k V u}{h} \text { and } \\
& 0=f u-\frac{k V v}{h} .
\end{aligned}
$$

Here, $u$ refers to the component of the horizontal motion in the direction of the horizontal pressure gradient force $F, v$ is the motion component parallel to the isobars, and $V$ is the magnitude of the wind. Symbol $f$ is the Coriolis parameter, $k$ is a dimensionless friction coef-

Corresponding author address: Thomas R. Parish, Dept. of Atmospheric Science, University of Wyoming, Laramie, WY 82071. E-mail: parish@uwyo.edu ficient, and $h$ refers to the height of the inversion layer. The last term in each equation represents frictional drag acting on the layer of air.

As noted by Radok (1973), Ball's theory was the first to explain satisfactorily the large-scale wind field over the Antarctic continent. Field studies (e.g., Streten 1963) and numerical analyses (e.g., Parish and Bromwich 1987) have shown the utility of Ball's approach. The forcing of the Antarctic surface winds according to Ball is the result of two processes that combine to form $F$ in (1): the horizontal pressure gradient force (PGF) arising from a temperature inversion over sloping terrain and the PGF in the free atmosphere above the radiatively cooled surface layer. The former is often referred to as the katabatic force (KF) or sloped-inversion PGF, and the latter is sometimes called the synoptic (SF) or background force. To understand Antarctic surface winds, knowledge of the magnitude and direction of these two forces is required. Ball also recognized that variations in the depth of the low-level flow contribute to $F$, although if it is assumed that the inversion follows the terrain or for scales greater than several kilometers, the term can be neglected (Ball 1960; Cassano 1998). As a result, Antarctic surface winds have been interpreted as due to the influence of both KF and SF. For terrain slopes greater than approximately 0.002 , corresponding to the entire coastal escarpment and extending approx- 


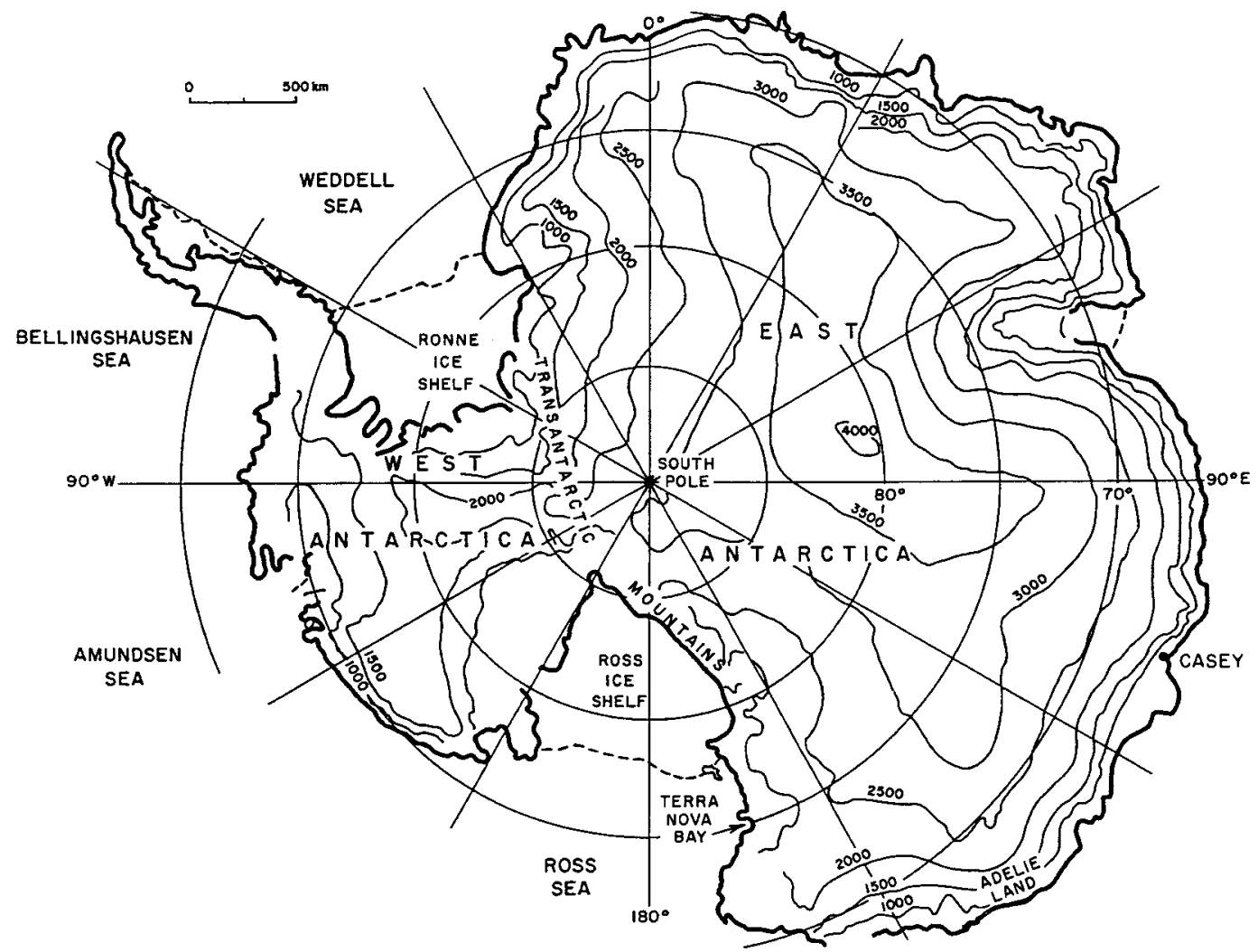

FIG. 1. Antarctic continent and selected geographical features.

imately to the 3000-m contour over most of East Antarctica (Fig. 1), scaling arguments proposed in Ball (1960) suggest that typical KF magnitudes exceed those arising from SF (Ball 1960). Ball interpreted the winds in the lower atmosphere over Antarctica as primarily katabatic. Others have advocated a different view and point to the importance of SF in explaining the Antarctic surface wind field (Radok 1973; Stone and Kahl 1991; Neff 1992, 1999; Phillpot 1997).

There is considerable uncertainty regarding the relationship between Antarctic surface winds and pressure gradients in the free atmosphere (Murphy and Simmonds 1993). Ball (1960) commented on the role played by synoptic-scale cyclones on the Antarctic near-surface wind field. Using theoretical arguments, he noted that the strongest surface winds should occur on the western side of the trough for coast-parallel moving cyclones. Tauber (1960) reached a similar conclusion based on observations along the coast of East Antarctica. Loewe (1974), however, noted that the strongest winds along Adélie Land $\left(67^{\circ} \mathrm{S}, 142^{\circ} \mathrm{E}\right.$; see Fig. 1) are associated with pressure falls in advance of cyclones. Furthermore, Bromwich (1989) indicated that the strongest surface winds at Terra Nova Bay $\left(75^{\circ} \mathrm{S}, 165^{\circ} \mathrm{E}\right)$ appear during periods in which the PGF over the Ross Sea is weak. Murphy and Simmonds (1993) have examined strong surface wind events near Casey station in East Antarc- tica and indicate that both KF and SF are important. They point to the potential importance of the cold air supply inland during strong wind cases, a point also noted in the modeling work of Parish (1984).

Observational evidence exists that suggests that the PGF in the upper levels of the atmosphere plays a role in establishing the boundary layer winds. Yasunari and Kodama (1993) found that the surface wind regime over Antarctica is inversely related to the strength of the tropospheric westerlies, a situation confirmed by observations discussed in Parish et al. (1993) and the numerical work of Simmonds and Law (1995). Neff (1999) has shown that the South Pole wind regime displays significant variability at synoptic timescales, and that the surface winds show clearly the influence of the PGF in the free atmosphere. Arpe and Cattle (1993), however, have examined the surface wind over Antarctica from operational model forecasts and comment that the observed surface winds were in general unrepresentative of the large-scale environment. Others (e.g., Wendler et al. 1993; Gallée et al. 1996; Wendler et al. 1997; Phillpot 1997) have also discussed the influence of the largescale environment on the Antarctic wind field.

Some of the difficulty relating Antarctic winds to the large-scale environment is no doubt the result of the sparse observational network over the high southern latitudes. In addition, numerical models are known to have 
difficulty simulating details of Antarctic meteorological processes because of problems in model physics (e.g., Cullather et al. 1997; Hines et al. 1999) and resolution of important topographic structure. Last, the Antarctic topography serves as a barrier to flows and large adjustments in the wind and pressure fields must take place. Ball (1960) has noted "that ordinary methods of meteorological analysis to describe the relation between the wind and synoptic pressure distribution must be used with caution."

The purpose of this paper is to infer the relative roles of $\mathrm{KF}$ and $\mathrm{SF}$ in forcing the wintertime surface wind regime over Antarctica. Section 2 describes the mean surface wind conditions over Antarctica depicted from the National Centers for Environmental Prediction (NCEP)-National Center for Atmospheric Research (NCAR) global reanalysis project (Kalnay et al. 1996). Section 3 describes the model formulation of the Antarctic wind field and the procedure for determining $\mathrm{KF}$ and SF from the NCEP-NCAR reanalysis (hereinafter $\mathrm{N}-\mathrm{N}$ ). A discussion of the results is provided in section 4 , and a summary is given in section 5 .

\section{The near-surface wind field over Antarctica}

Topography has long been known to exhibit strong control on the surface wind field over the Antarctic continent. Meteorological observations at manned sites and automatic weather stations (AWS) along the steep coastal ice slopes of East Antarctica reveal that the underlying terrain is the central influence on the low-level flows throughout the year. Schwerdtfeger (1970) summarized the dominant role of topography by noting that "the prevailing surface wind direction and strength is so closely related to the direction and steepness of the slope of the terrain that the former two values can well be estimated if the topography is known and vice versa." Antarctic surface winds are among the most persistent on earth, reflecting clearly the underlying ice topography (Parish 1982a, 1988). Annual resultant wind directions are generally $20^{\circ}-50^{\circ}$ to the left of the fall line (vector pointing downslope), consistent with Coriolis deflection of gravity-driven flows as described in (1) and (2). The high directional constancy of the winds in the lower atmosphere is found throughout the year. The directional persistence displayed by the surface wind during nonwinter months is puzzling, given that the coastal rim of Antarctica is subject to frequent and intense cyclonic activity. AWS data (Keller et al. 1994) show that the passage of cyclones to the north of the continent modulates surface wind speeds, although the directional changes are less pronounced. This implies an active link between the continental topography and the large-scale PGF in the atmosphere in establishing the direction of the surface wind. This issue will be addressed later.

An emphasis in this paper will be placed on timeaveraged conditions from the winter period of June,
July, and August (JJA) of 1997 over East Antarctica. Model output sets over Antarctica have been obtained from the $\mathrm{N}-\mathrm{N}$. The resolution of $\mathrm{N}-\mathrm{N}$ is T62 $(209 \mathrm{~km})$ with 28 vertical sigma levels. Values of state variables were interpolated from Gaussian space to a $2.5^{\circ} \times 2.5^{\circ}$ latitude-longitude grid at 0000, 0600, 1200, and 1800 UTC time intervals. Mean monthly datasets were then constructed by simple averaging.

The validity of the $\mathrm{N}-\mathrm{N}$ for Antarctic conditions is not known with certainty. Cullather et al. (1997) have evaluated the performance of operational models in simulating Antarctic conditions. The authors note that the NCEP results have improved considerably over the Antarctic continent since 1985, although comparison of simulated surface winds with observations is difficult because of issues of model resolution and data quality. Maps presented by Cullather et al. (1997) show, however, that NCEP time-averaged surface wind vectors over Antarctica are consistent with previous work (Parish and Bromwich 1987). Recently, Bromwich et al. (1999) have evaluated the NCEP model performance during the First Regional Observing Study of the Troposphere (FROST). They note that problems exist with the initial fields used by the models, although it is acknowledged that the sparse observational network makes detailed comparison difficult. In particular, the surface inversion was shown to be weaker than previous studies indicate. Despite this apparent shortcoming, the authors conclude that the wind directions near the surface are reasonable during FROST. Hines et al. (1999) specifically examined the $\mathrm{N}-\mathrm{N}$ and note some problems with the surface energy budget. Surface temperatures are generally realistic, however, because errors contained within individual terms in the surface energy budget equation cancel.

Figure 2 depicts the mean wind vectors and wind speeds over Antarctica from the N-N for the winter months JJA of 1997 at $\sigma=0.995$, approximately $35 \mathrm{~m}$ above the Antarctic ice surface. Wind vectors show a close relationship to the underlying terrain, with the strongest winds situated over the steep coastal ice slopes. Time-averaged wind vectors are in agreement with previous streamline depictions (Parish and Bromwich 1987). Simulated wind speeds from the N-N fields are in reasonable agreement with observed values at manned and AWS sites about the continent. The strongest wind speeds of $15 \mathrm{~m} \mathrm{~s}^{-1}$ are typical of mean-monthly averages at manned coastal stations. The location of the wind maxima is also in agreement with known strong wind zones, such as along Adélie Land.

\section{Forcing of Antarctic surface winds}

Ball (1960) has shown that the solution to (1) and (2) can be expressed as 


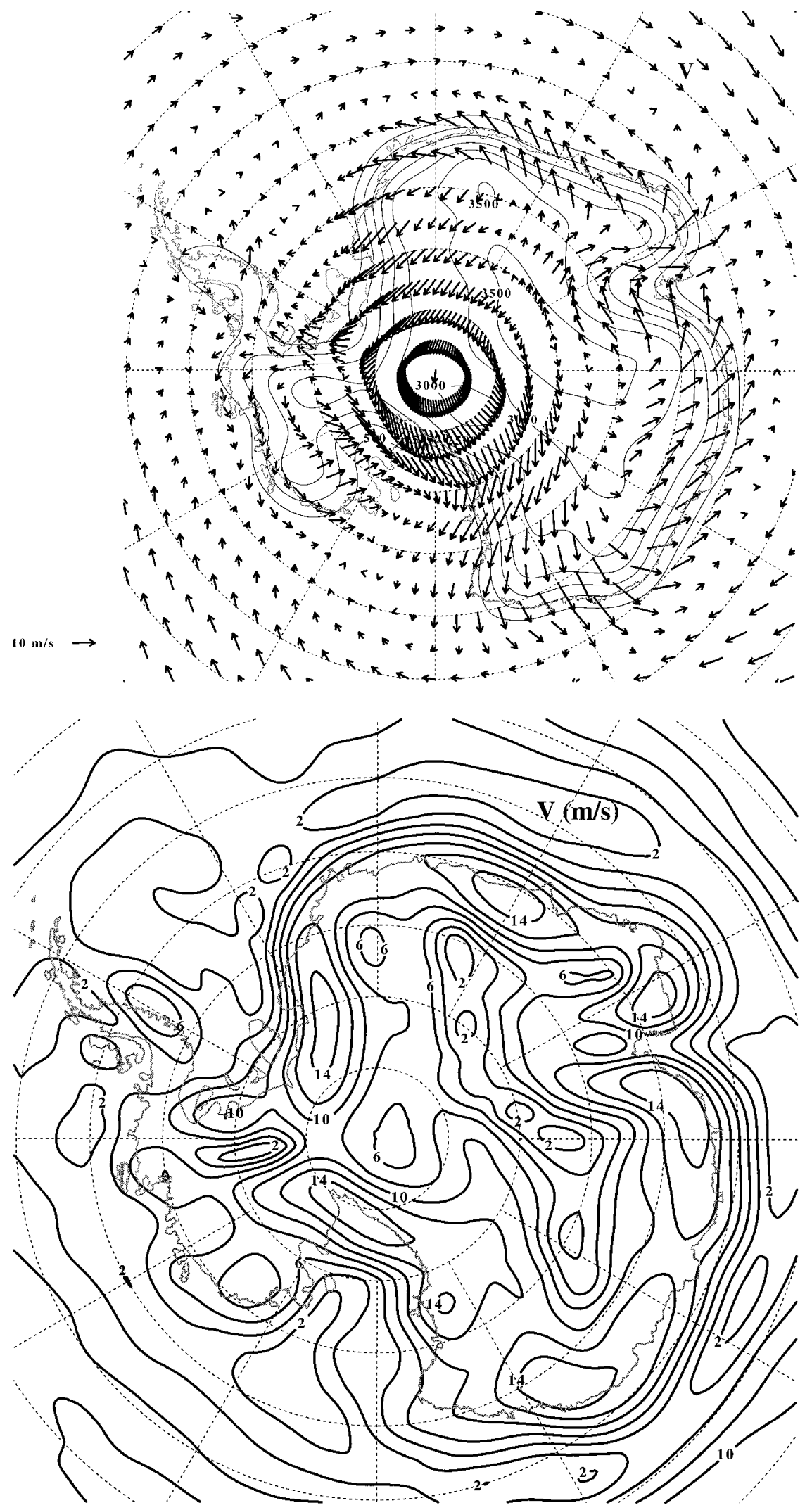

FIG. 2. (top) Mean wind vectors and (bottom) wind speeds $\left(\mathrm{m} \mathrm{s}^{-1}\right)$ at $\sigma=0.995$ (approximately $35 \mathrm{~m}$ above ground level) for Jun, Jul, Aug of 1997 from NCEP-NCAR reanalysis project. Antarctic terrain contour heights (m) represented by thin solid lines (top). 


$$
\begin{aligned}
V & =\left(\frac{h F}{k}\right)^{1 / 2} \cos ^{1 / 2} \beta=\frac{F}{f} \sin \beta, \\
\cos \beta & =\left(1+J^{2}\right)^{1 / 2}-J, \text { and } \\
J & =\frac{h f^{2}}{2 k F} .
\end{aligned}
$$

Here, $u=V \cos \beta$ and $v=V \sin \beta$, and $\beta$ can thus be viewed as the angle of the wind from the PGF, term $F$. Ball (1960) noted that $V$ and $\beta$ can be determined when $F$ and $k / h$ are known. For the analyses to follow, $V$ and $k / h$ are assumed to be known and $\beta$ and $F$ can then be determined. The limiting requirements for the use of (3)-(5) are the assumptions of a steady-state flow, negligible inertia effects, and that the form of the friction force is representative. For the mean-monthly wintertime averages and grid spacing of the $\mathrm{N}-\mathrm{N}$, the former two assumptions are justified. Sensitivity experiments incorporating a range of values of $k$ are required before the latter assumption can be evaluated.

To understand the forcing of Antarctic surface winds, PGF must be resolved into KF and SF. The horizontal pressure gradient $F$ in the downslope direction can be expressed (Mahrt 1982):

$$
F=g \frac{d}{\Theta_{o}} \sin \alpha-\cos \alpha \frac{g}{\Theta_{o}} \frac{\partial(\bar{\Theta} h)}{\partial s}-\frac{1}{\rho} \frac{\partial p}{\partial s_{\mathrm{syn}}} .
$$

This formulation is similar to that proposed by Ball (1960). Here, $g$ is the acceleration due to gravity, and $d$ is the potential temperature deficit, the difference in potential temperature at any point in the katabatic layer between the radiatively cooled layer and the ambient atmosphere. The term $\alpha$ refers to the terrain slope (a product of $\mathrm{N}-\mathrm{N}), h$ is the height of the diabatically cooled layer, $\Theta_{o}$ is the background potential temperature at a particular level, and $s$ refers to a horizontal distance (approximately $200 \mathrm{~km}$ for the analyses to follow). Other symbols have their usual meteorological meaning. The first term on the right represents KF. The second term represents the effects of the change in the depth and/or cooling of the katabatic layer in the downslope direction on the acceleration, and the third term is SF.

Cassano (1998) has shown that it is possible to infer each of these terms from numerical models, provided that the total PGF is one of the model output variables, and thereby depict the momentum balance of low-level Antarctic flows. If the actual model PGF is not available, it is difficult to reconstruct the PGF on sigma surfaces from state variables alone to determine SF. Formulation of the PGF on sigma surfaces involves two large terms of opposite sign and approximately equal magnitudes; the inferred PGF represents the small difference between the two terms. Interpolation of the PGF from temperature and surface pressures over sloping terrain is thus subject to large errors that in general mask the actual solution. Because the PGF is not part of the output

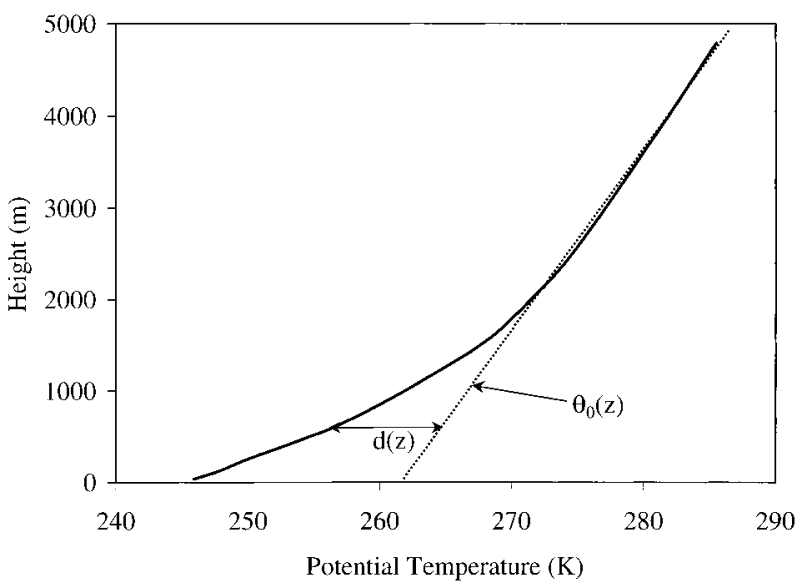

FIG. 3. Vertical profile of potential temperature (solid line) for Jul of 1997 at $70^{\circ} \mathrm{S}, 142.5^{\circ} \mathrm{E}$. Dashed line represents potential temperature profile in ambient atmosphere; $d(z)$ is the potential temperature deficit; $\theta_{0}(z)$ is the reference potential temperature.

set in $\mathrm{N}-\mathrm{N}$, indirect methods must be used to determine SF.

Determination of KF is graphically represented in Fig. 3 , which shows the mean July potential temperature profile for the grid point at $70^{\circ} \mathrm{S}, 142.5^{\circ} \mathrm{E}$ (Adélie Land). The dashed line in Fig. 3 refers to the ambient potential temperature profile, computed by fitting a line to the potential temperatures in a layer between 1500 and 5000 $\mathrm{m}$ above the ice surface and presumably above the influence of strongest diabatic cooling. This line is assumed to represent the temperature profile in the free atmosphere. The difference between the sigma-level potential temperature and the inferred potential temperature in the ambient environment is the potential temperature deficit. Multiplication of the deficit by the terrain slope and the known term $g / \Theta_{O}$, where $\Theta_{O}$ is the ambient potential temperature at the level of interest, yields KF.

The second rhs term in (6) represents the effect of changes in the height of the inversion along the surface. This term can be calculated directly from N-N. Cassano (1998) has shown that this term is at least an order of magnitude smaller than KF and SF except at the coastal grid point in his high-resolution model simulations. As noted earlier, Ball (1960) noted that this term was in general smaller over length scales in excess of a few kilometers. Over small scales, this term can be important, as is evidenced in Ball (1956). In N-N, having a grid resolution in excess of $200 \mathrm{~km}$, this term is expected to be small. Results from N-N showed this term was negligible over the entire continent with the exception of the single grid point at the coast. The following discussion will thus focus only on KF and SF.

As noted above, SF requires indirect determination. It will be assumed that the residual between $\mathrm{KF}$ and the total PGF is primarily due to SF. The total PGF will be estimated using the Ball (1960) model. Vector subtrac- 


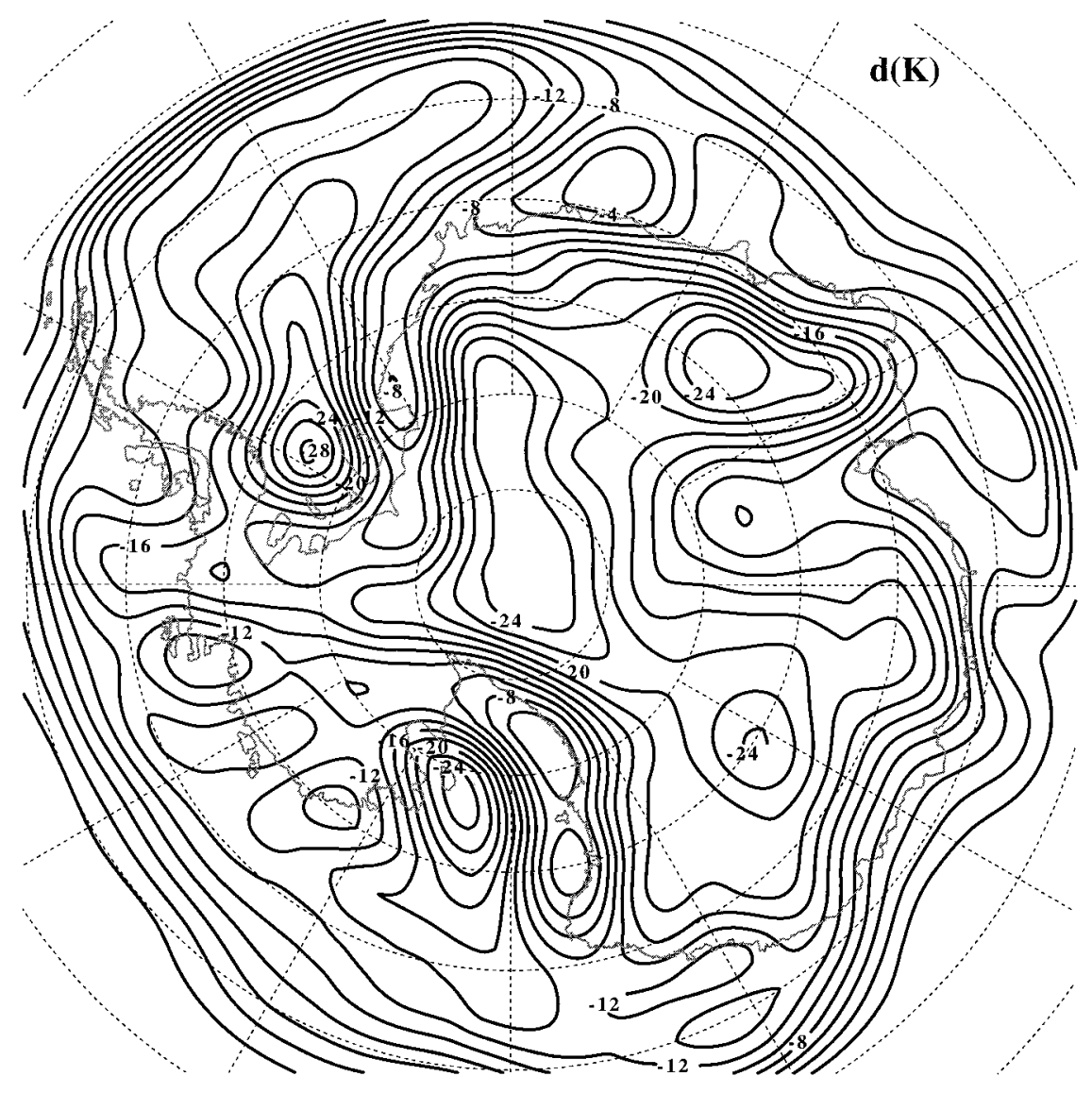

FIG. 4. Time-averaged potential temperature deficit (K) for Jun, Jul, Aug of 1997 from NCEPNCAR reanalysis project.

tion of KF from the total PGF will provide an estimate for SF.

Figure 4 illustrates the potential temperature deficit at the lowest sigma surface for the JJA 1997 period. Deficits of $-24 \mathrm{~K}$ are found over the gently sloping continental interior, decreasing to less than $-10 \mathrm{~K}$ over the coastal margins. Large deficits are also depicted over both the Ross and Ronne Ice Shelves. The deficit pattern shown in Fig. 4 is similar to previous representations of the surface inversion strength (Schwerdtfeger 1984, p. 31), as is to be expected. The potential temperature deficits are also consistent with the intensity of the wind (Fig. 2), reflecting the role of mixing processes. The strongest winter time temperature inversions (potential temperature deficits) are associated with weak winds. Strong surface winds over the steep coastal terrain enhance the mixing process, thereby reducing the strength of the inversion and hence the magnitude of the potential temperature deficit.

Calculation of KF from N-N for JJA of 1997 follows from (6) as noted above. The vector representation and the magnitudes of KF are shown in Fig. 5. Here, KF is scaled by the Coriolis parameter; the magnitude of each $\mathrm{KF}$ vector thus represents an equivalent geostrophic val- ue. The direction of $\mathrm{KF}$ is down the local fall line. Largest values of KF at $\sigma=0.995$ are found over the steep coastal slopes where magnitudes of equivalent geostrophic wind speeds exceed $20 \mathrm{~m} \mathrm{~s}^{-1}$. Maxima in KF coincide with maxima in wind speed shown in Fig. 2. Equivalent KF geostrophic wind magnitudes often exceed the magnitudes of the respective surface wind in Fig. 2, especially near the steep coastal sections of Antarctica. This feature is a prerequisite if KF is the dominant force, because surface winds are significantly reduced by the effect of friction. The equivalent geostrophic wind maxima associated with KF are aligned along regions of converging surface wind streamlines, or confluence zones (Parish and Bromwich 1987). Converging drainage currents enhance the upslope supply of negatively buoyant air available to downslope sections of Antarctica and have been tied to the extreme wind conditions at locations such as Adélie Land. There is thus indirect observational support for the KF pattern shown in Fig. 5.

Calculation of $\mathrm{KF}$ is straightforward, and there is no reason to doubt the broad-scale field shown in Fig. 5. Determination of SF is not as simple, and care is required in order to arrive at reasonable estimates of this 


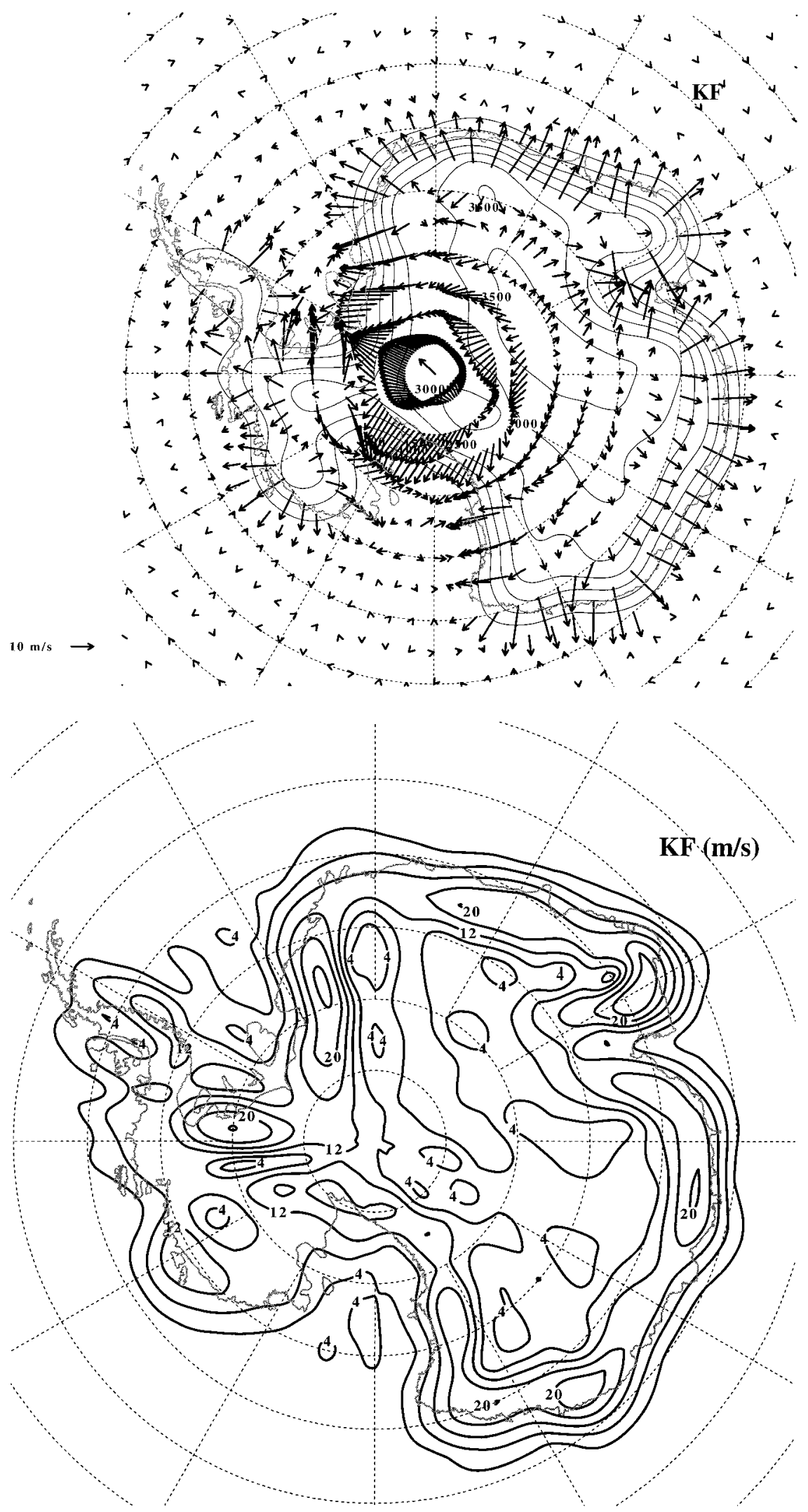

FIG. 5. (top) Vectors and (bottom) magnitude of equivalent geostrophic wind $\left(\mathrm{m} \mathrm{s}^{-1}\right)$ of the katabatic component of the total pressure gradient force for Jun, Jul, Aug of 1997 from NCEPNCAR reanalysis project. 
component. It is necessary to determine first the total PGF $F$ using (3)-(5). The assumed form of friction is highly idealized in the Ball model and can only be viewed as an approximation. However, $F$ is sensitive to the assumed value of $k$ so it is important to estimate the friction force as accurately as possible.

To achieve some confidence regarding the value $k$ in Ball's friction term, a series of numerical experiments were performed with the Fifth-Generation Pennsylvania State University-NCAR Mesoscale Modeling System (MM5) over a section of East Antarctic terrain (Cassano 1998). Vertical grid spacing was set up so as to provide similar resolution as in $\mathrm{N}-\mathrm{N}$. Because the friction force is known in the MM5 simulations, it is possible to determine representative values of $k$ for the Ball model. Simulations were conducted for a $24-\mathrm{h}$ period by which time the surface winds were fully developed. To arrive at an estimate for $k$, the friction force from MM5 at the lowest sigma level was divided by the wind speed and then multiplied by the height of the diabatically cooled layer $h$. Results reveal a range of friction forces depending on the boundary layer scheme used in MM5. This result also points out the approximate nature of the Ball friction term. Simulations revealed that the friction force at the $35-\mathrm{m}$ level of the $\mathrm{N}-\mathrm{N}$ was particularly sensitive to the boundary layer depth. A constant value of $k / h$ of $1.9 \times 10^{-5} \mathrm{~m}^{-1}$ was selected as representative. This result is comparable to $k / h$ values of $2.5 \times 10^{-5}$ and $1.7 \times 10^{-5} \mathrm{~m}^{-1}$ suggested by Ball (1960) as representative of Antarctic flows over the coastal and interior ice slopes, respectively. The value of $k / h$ of 1.9 $\times 10^{-5} \mathrm{~m}^{-1}$ was used in all subsequent analyses.

Given the uncertainty in the friction force and application of the Ball model in general, results for both $F$ and the SF should be viewed in a qualitative rather than quantitative manner. Figure 6 depicts the total PGF $F$ for the JJA 1997 period over Antarctica. It is apparent from Fig. 6 that the total PGF over the Antarctic continent is closely tied to the underlying ice terrain. The link between $F$ and the ice contours is expected because the wind vectors shown in Fig. 2 display a close relationship to the underlying terrain. The largest values of $F$ are situated over the steeply sloping coastal ice slopes, similar to KF. The magnitudes of $F$ in Fig. 6 can be seen to exceed those of KF, suggesting that the winds, in general, are forced by an SF component as well.

Estimates of SF can be obtained by vector subtraction of KF from $F$. Figure 7 illustrates the results for the JJA 1997 period. The most striking feature is again the apparent relationship between the terrain and the orientation of the SF vectors. Largest magnitudes are depicted over the steep coastal slopes; SF contributes roughly one-half of the total magnitude of $F$. This result implies that SF is an important component of the total forcing of the Antarctic surface wind. Although the SF field is more sensitive to the choice of $k$ than is either KF or $F$, the relationship of SF to the Antarctic terrain in Fig. 7 is thought to be at least qualitatively correct.
Analyses using a range of $k$ values (not shown) depict a similar relationship between SF and the Antarctic terrain.

Results suggest that SF over Antarctica is significantly different from the PGF to the north of the continent, implying that the continental topography acts to shape the ambient horizontal pressure field. This feature of SF may be one reason for the lack of consistency in previous studies regarding the observed low-level Antarctic winds and the large-scale horizontal pressure gradients. Extrapolation of the pressure field over the ocean north of Antarctica onto the continental surface may lead to large errors in the magnitude and direction of the PGF.

\section{Discussion}

Two important conclusions can be made from the preceding analyses. First, SF is a vital component of the PGF in forcing the low-level Antarctic wind field during the winter period. Second, SF is coupled to the underlying Antarctic terrain and the direction of this force is similar to KF. Throughout this discussion, the term "katabatic" has been used with caution when describing Antarctic flows. Direction alone is insufficient in discriminating katabatic flows from those forced through other processes. Results from above suggest that winds forced solely by SF would result in flows along pathways similar to pure katabatic flows.

There is indirect support for the role of SF as an important factor is forcing low-level winds over Antarctica. Resultant wind statistics from manned stations (Parish 1988) and AWS (e.g., Keller et al. 1994) show that the summertime Antarctic surface winds display nearly the same directional constancy and wind direction as during winter. Potential temperature deficits from $\mathrm{N}-\mathrm{N}$ during the summer months (not shown) are negligible over nearly the entire continent. This implies that SF dominates the total PGF. The only means by which the summertime surface winds can attain their observed persistence along predominantly katabatic pathways is for the SF to display a similar relationship to the Antarctic terrain as seen during winter.

Given the significance of the SF on the low-level wind, it seems logical to inquire as to its evolution so as to become directed primarily in a downslope direction. As noted by Schwerdtfeger (1984), Antarctica is unique in terms of geographical characteristics. The entire south-polar region consists of an elevated ice continent encircled by the great Southern Ocean. A semipermanent frontal boundary is found near the continental ice edge and a pronounced horizontal temperature gradient between Antarctica and the subpolar latitudes of the Southern Hemisphere persists throughout the year. The ice sheet is considerably colder than the atmosphere to the north of the continent throughout the year. As suggested by Kodama et al. (1989), the large-scale horizontal temperature gradient may also be responsible for 

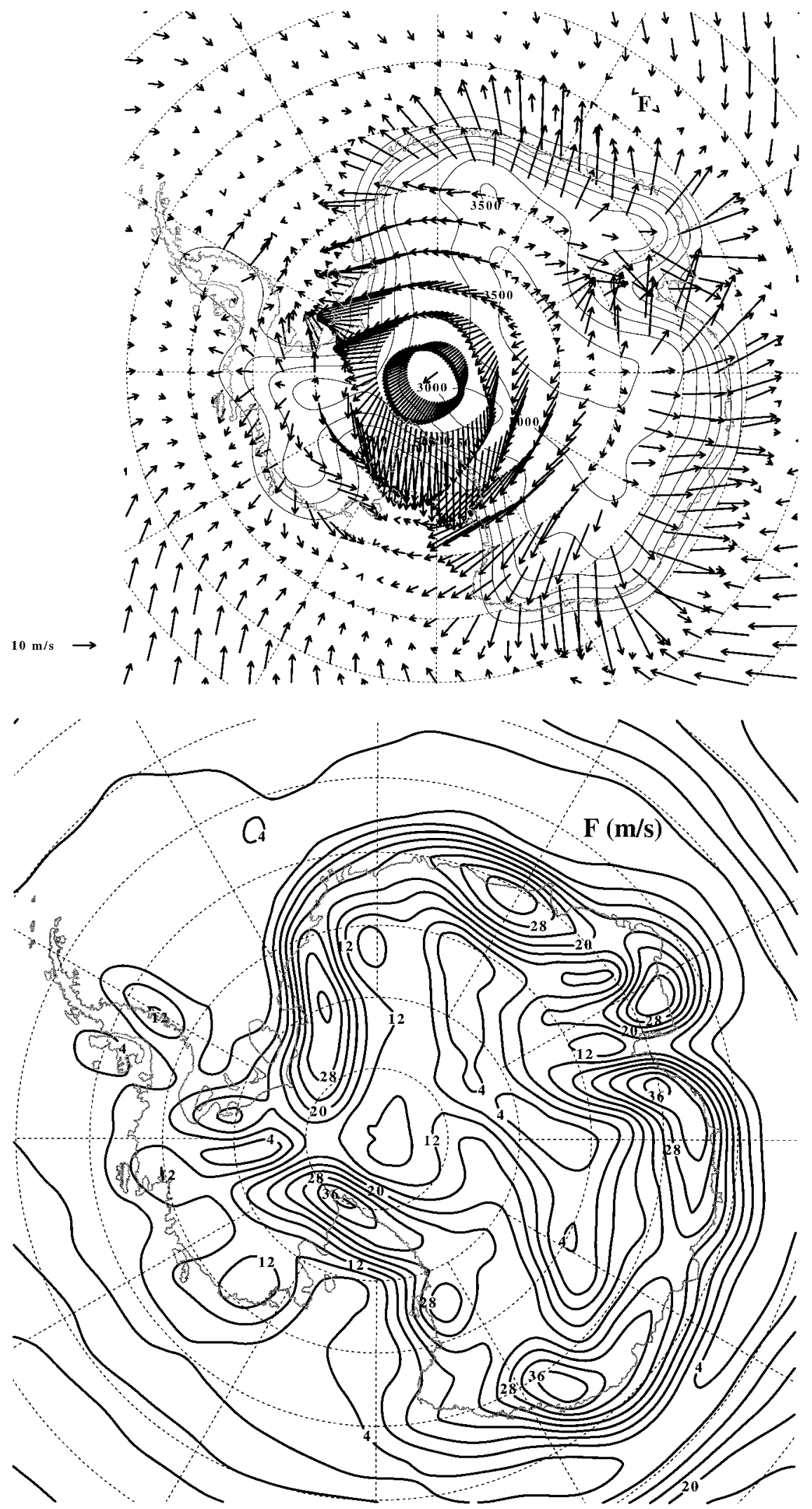

FIG. 6. As in Fig. 5, but for the total pressure gradient force. 

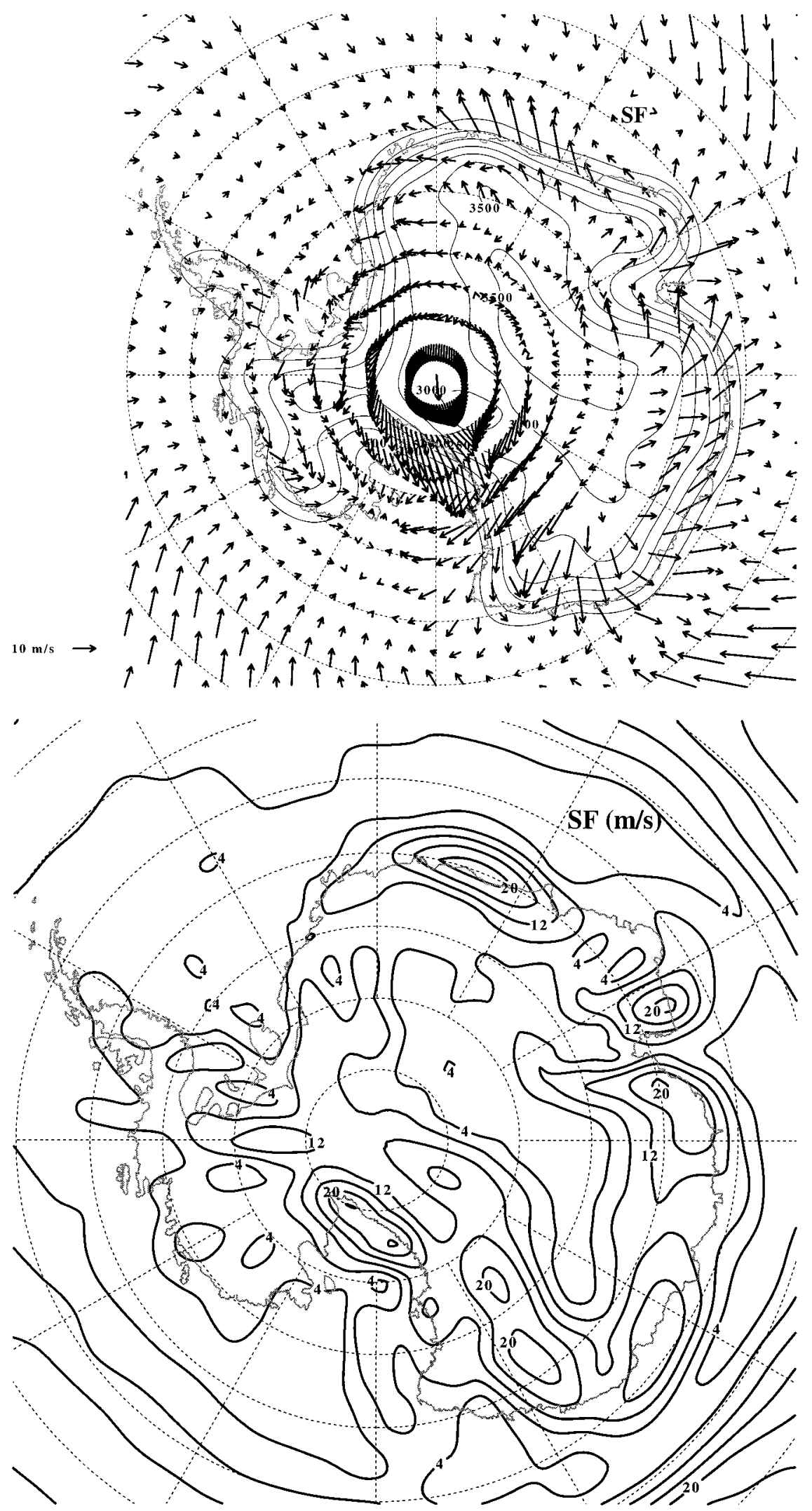

FIG. 7. As in Fig. 5, but for the synoptic component of the total pressure gradient force. 
a low-level wind regime similar to a thermally direct circulation modified by the earth's rotation. The resulting meridional circulation is forced most strongly above the steep coastal slopes where the horizontal temperature gradient is largest. The effect of such large-scale horizontal temperature gradients is independent of KF, which is forced by local diabatic cooling processes.

Migrating cyclonic circulations about the Antarctic continent may be another contributing factor. Significant adjustments occur as the stable air impinges on the steep Antarctic coastal escarpment. Schwerdtfeger (1975) was the first to examine the impingement of stable air against the Antarctica barrier. The air mass undergoes adjustment to a near-geostrophic state and the resulting flows, or "barrier winds," are directed parallel to the terrain. Parish (1982b, 1983) has conducted numerical experiments of the process. Others, including Richwein (1980), Pierrehumbert and Wyman (1985), Stauffer and Warner (1987), Bell and Bosart (1988), and Xu (1990), have investigated the effect of the terrain blocking of stable air. The relevant features of these barrier winds are that 1 ) the orography modifies the existing ambient pressure field, resulting in a pressure gradient force that is dependent on the terrain slope and 2) the near-surface flows are directed with a significant component parallel to the terrain contours. These characteristics are similar to the Antarctic situation.

Perhaps the term "synoptic" force is misleading when describing the ambient atmosphere over the Antarctic continent as seen in the mean monthly averages. This force is intimately tied to the terrain, as is KF, and differs markedly from the PGF to the north of the continent. The synoptic force over Antarctica offers testimony to the active role played by the ice terrain in shaping the wind field.

\section{Summary}

Antarctic surface winds throughout the year are highly persistent and have directions clearly related to the fall line of the underlying terrain. The low-level wind regime has often been interpreted as katabatic owing to the strong coupling between the wind direction and topography. Analyses of state variables produced from $\mathrm{N}-\mathrm{N}$ have provided a means to estimate the forcing of the mean monthly surface winds over Antarctica.

Using the model proposed by Ball (1960), the total PGF for Antarctic winds can be estimated from the wind field. Profiles of potential temperature for time-averaged period characteristic of winter months of June, July, and August of 1997 were used to determine the potential temperature deficit in the near-surface layer over Antarctica and hence KF. Vector subtraction of the KF component from the total PGF yields an estimate for SF. Analyses suggest that KF is a significant component to the total PGF. It is not possible, however, to explain the wintertime wind field from the KF alone. Here, SF is an important component to the winter low-level Antarctic flow regime.

The synoptic force is influenced by the Antarctic orography, being directed with a significant downslope component. In a qualitative sense, SF resembles KF owing to the direction of the forcing. The existence of a downslope-directed SF is necessary to explain the persistence of the summertime Antarctic low-level winds. It is thus inappropriate to conclude that Antarctic winds are katabatic simply because they are directed along favored topographic pathways.

Acknowledgments. This research was funded in part by National Science Foundation Grant OPP-9725263.

\section{REFERENCES}

Arpe, K., and H. Cattle, 1993: A comparison of surface stress and precipitation fields in short-range forecasts over the Antarctic region. J. Geophys. Res., 98, 13 035-13044.

Ball, F. K., 1956: The theory of strong katabatic winds. Aust. J. Phys., 9, 373-386.

, 1957: The katabatic winds of Adélie Land and King George V Land. Tellus, 9, 201-208.

- 1960: Winds on the ice slopes of Antarctica. Antarctic Meteorology, Proceedings of the Symposium in Melbourne, 1959. Pergamon, 9-16.

Bell, G. D., and L. F. Bosart, 1988: Appalachian cold-air damming. Mon. Wea. Rev., 116, 137-161.

Bromwich, D. H., 1989: An extraordinary katabatic wind regime at Terra Nova Bay, Antarctica. Mon. Wea. Rev., 117, 688-695.

, R. I. Cullather, and R. W. Grumbine, 1999: An assessment of the NCEP Operational Global Spectral Model forecasts and analyses for Antarctica during FROST. Wea. Forecasting, 14, 835850.

Cassano, J. J., 1998: The impact of numerical model configuration on simulated Antarctic katabatic winds. Ph.D. Thesis, University of Wyoming, 216 pp. [Available from the Department of Atmospheric Science, University of Wyoming, Laramie, WY 82071.]

Cullather, R. I., D. H. Bromwich, and R. W. Grumbine, 1997: Validation of operational numerical analyses in Antarctic latitudes. J. Geophys. Res., 102, 13 761-13 784.

Gallée, H., P. Pettré, and G. Schayes, 1996: Sudden cessation of katabatic wind in Adélie Land, Antarctica. J. Appl. Meteor., 35, 1142-1152.

Hines, K. M., R. W. Grumbine, D. H. Bromwich, and R. I. Cullather, 1999: Surface energy balance of the NCEP MRF and NCEPNCAR reanalysis in Antarctic latitudes during FROST. Wea. Forecasting, 14, 851-866.

Kalnay, E., and Coauthors, 1996: The NCEP/NCAR 40-Year Reanalysis Project. Bull. Amer. Meteor. Soc., 77, 437-471.

Keller, L. M., G. A. Weidner, and C. R. Stearns, 1994: Antarctic Automatic Weather Station Data for the Calendar Year 1992. Department of Atmospheric and Oceanic Sciences, University of Wisconsin-Madison, 356 pp. [Available from the Department of Atmospheric and Oceanic Sciences, University of Wisconsin-Madison, Madison, WI 53706.]

Kodama, Y., G. Wendler, and N. Ishikawa, 1989: The diurnal variation of the boundary layer in summer in Adélie Land, Eastern Antarctica. J. Appl. Meteor., 28, 16-24.

Loewe, F, 1974: Considerations concerning the winds of Adélie Land. Gletscherk. Glazialgeol., 10, 189-197.

Mahrt, L., 1982: Momentum balance of gravity flows. J. Atmos. Sci., 39, 2701-2711.

Murphy, B. F., and I. Simmonds, 1993: An analysis of strong wind 
events simulated in a GCM near Casey in the Antarctic. Mon. Wea. Rev., 121, 522-534.

Neff, W. D., 1992: Synoptic influence on inversion winds at the South Pole. Third Conf. on Polar Meteorology and Oceanography, Portland, OR, Amer. Meteor. Soc., 24-28.

_ 1999: Decadal-time-scale trends and variability in the tropospheric circulation over the South Pole. J. Geophys. Res., 104, 27 217-27 251.

Parish, T. R., 1982a: Surface airflow over East Antarctica. Mon. Wea. Rev., 110, 84-90.

— 1982b: Barrier winds along the Sierra Nevada Mountains. J. Appl. Meteor., 21, 925-930.

_ 1983: The influence of the Antarctic Peninsula on the windfield over the western Weddell Sea. J. Geophys. Res., 88, 2684-2692.

_ 1984: A numerical study of strong katabatic winds over Antarctica. Mon. Wea. Rev., 112, 545-554.

_ 1988: Surface winds over the Antarctic continent: A review. Rev. Geophys., 26, 169-180.

— , and D. H. Bromwich, 1987: The surface windfield over the Antarctic ice sheets. Nature, 328, 51-54.

— P. Pettré, and G. Wendler, 1993: The influence of large scale forcing on the katabatic wind regime of Adélie Land, Antarctica. Meteor. Atmos. Phys., 51, 165-176.

Phillpot, H., 1997: Some observationally identified meteorological features of East Antarctica. Meteorology Study 42, Bureau of Meteorology, Melbourne. [Available from the Bureau of Meteorology, GPO Box 1289K, Melbourne, Victoria 3001, Australia.]

Pierrehumbert, R. T., and B. Wyman, 1985: Upstream effects of mesoscale mountains. J. Atmos. Sci., 42, 977-1003.

Radok, U., 1973: On the energetics of surface winds of the Antarctic ice cap. Energy fluxes over polar surface, WMO Tech. Note 129, World Meteor. Org., Geneva, Switzerland, 69-100.
Richwein, B. A., 1980: The damming effect of the southern Appalachians. Nat. Wea. Dig., 5, 2-12.

Schwerdtfeger, W., 1970: The climate of the Antarctic. World Survey of Climatology, S. Orvig, Ed., Elsevier, 253-355.

_ 1975: The effect of the Antarctic Peninsula on the temperature regime of the Weddell Sea. Mon. Wea. Rev., 103, 41-51.

- 1984: Weather and Climate of the Antarctic. Elsevier, 261 pp.

Simmonds, I., and R. Law, 1995: Associations between Antarctic katabatic flow and the upper level winter vortex. Int. J. Climatol., 15, 403-422.

Stauffer, D., and T. T. Warner, 1987: A numerical study of Appalachian cold air damming and coastal frontogenesis. Mon. Wea. Rev., 115, 799-821.

Stone, R. S., and J. D. Kahl, 1991: Variations in boundary layer properties associated with clouds and transient weather disturbances at the South Pole during winter. J. Geophys. Res., 96, $5127-5144$.

Streten, N. A., 1963. Some observations of Antarctic katabatic winds. Aust. Meteor. Mag., 42, 1-23.

Tauber, G. M., 1960: Characteristics of Antarctic katabatic winds. Antarctic Meteorology, Proceedings of the Symposium in Melbourne, 1959. Pergamon, 52-64.

Wendler, G., J. C. André, P. Pettré, J. Gosink, and T. Parish, 1993: Katabatic winds in Adélie Land. Antarctic Meteorology and Climatology: Studies Based on Automatic Weather Stations, Antarctic Research Series, Vol. 61, D. H. Bromwich and C. R. Stearns, Eds., Amer. Geophys. Union, 23-46.

- C. Stearns, G. Weidner, G. Dargaud, and T. Parish, 1997: On the extraordinary katabatic winds of Adélie Land. J. Geophys. Res., 102, 4463-4474.

Xu, Q., 1990: A theoretical study of cold air damming. J. Atmos. Sci., 47, 2969-2985.

Yasunari, T., and S. Kodama, 1993: Intraseasonal variability of katabatic wind over East Antarctica and planetary flow regime in the Southern Hemisphere. J. Geophys. Res., 98, 13 063-13 070. 